\title{
A net-jet flow system for mass transfer and microsensor studies of sinking aggregates
}

\author{
Helle Ploug ${ }^{1,2, *}$, Bo Barker Jørgensen ${ }^{2}$ \\ ${ }^{1}$ Institute of Biological Sciences, Dept of Microbial Ecology, University of Aarhus, Ny Munkegade Building 540. \\ DK-8000 Aarhus C. Denmark \\ ${ }^{2}$ Max Planck Institute for Marine Microbiology, Celsiusstr. 1, D-28359 Bremen, Germany
}

\begin{abstract}
A flow system was developed which enables studies of hydrodynamics and mass transfer in freely sinking aggregates. The aggregates stabilized their positions in the water phase at an upward flow velocity which balanced and opposed the sinking velocity of the individual aggregate. The flow field was shown to be laminar at flow velocities ranging from 40 to $200 \mathrm{~m} \mathrm{~d}^{-1}$, which cover typical sinking velocities of aggregates in the ocean. A viscous boundary layer with steep gradients of flow velocity was measured around sinking aggregates by flow visualization techniques. Velocity gradients in the viscous boundary layer along the sides of the aggregate parallel to the flow could by explained by creeping flow, while a non-turbulent wake was present at the rear (downstream) of the aggregate. The oxygen distribution inside a ca $3.5 \mathrm{~mm}$ large diatom aggregate and in the surrounding water was mapped in 2 dimensions from 360 microelectrode measurements. The data showed the existence of a diffusive boundary layer surrounding the aggregate, which indicates that the radial transport of solutes occurred by molecular diffusion. The diffusive boundary layer thickness was $0.38 \mathrm{~mm}$ upstream, $0.85 \mathrm{~mm}$ along the sides, and $1.0 \mathrm{~mm}$ downstream. The oxygen microenvironment of aggregates changed dramatically when they were sitting on a solid surface compared with when they were sinking.
\end{abstract}

KEY WORDS: Diffusive boundary layers - Flow gradients $\mathrm{O}_{2}$ gradients Photosynthesis - Respiration

\section{INTRODUCTION}

A significant fraction of organic matter in the ocean and in lakes occurs as sinking aggregates, which are larger than $0.5 \mathrm{~mm}$ and mainly composed of phytoplankton, bacteria, and detritus (Alldredge \& Silver 1988, Grossart \& Simon 1993, Grossart et al. 1998). The settling velocities of such aggregates in the ocean vary widely, with mean values of $74 \pm 39 \mathrm{~m} \mathrm{~d}^{-1}$ (Alldredge \& Gotschalk 1988), and sinking aggregates comprise a significant fraction of the vertical carbon flux in the ocean (Shanks \& Trent 1980). The mechanisms of mass transfer between sinking aggregates and the surrounding water may govern the growth conditions for microorganisms within the aggregates, e.g. through chemical diffusion gradients or particle trapping dur-

\footnotetext{
- Present address: Marine Biological Laboratory, University of Copenhagen, Strandpromenaden 5, DK-3000 Helsingør, Denmark. E-mail: helle-ploug@inet.zitech.dk
}

ing settling, but quantitatively these mechanisms are poorly understood in the ocean due to few experimental data. The impact of advective flow through porous aggregates on particle scavenge rates and nutrient availability for phytoplankton and bacteria in sinking aggregates has been discussed and estimated through model calculations (Logan \& Hunt 1987, Logan \& Alldredge 1989, Stolzenbach 1993). Transparent exopolymeric particles (TEP) are, however, often found in marine aggregates (Alldredge et al. 1993, Passow et al. 1994), whereby advective processes may be limited inside the aggregates. Intra-aggregate flow velocities have never been directly quantified because the experimental techniques have not been developed for such measurements. Alldredge \& Cohen (1987) demonstrated steep gradients of oxygen and $\mathrm{pH}$ in marine snow and fecal pellets, which indicate that mass transfer mainly occurs by molecular diffusion. The aggregates were placed in a small cone made of a plankton net and turbulence was induced by a pipette 
producing air bubbles from below. Here, we present a simple flow system in which mass transfer can be studied experimentally in freely sinking aggregates. The aggregates were kept in suspension by adjusting an upward oriented flow velocity to oppose and balance the sinking velocity of the aggregate. Microelectrode measurements could then be made through the entire aggregate at a high spatial resolution of $<0.05 \mathrm{~mm}$. The experimental set up provides a simple new approach to study mass transfer and biological activity in single marine aggregates such as marine snow, plankton colonies or fecal pellets during sinking.

\section{MATERIALS AND METHODS}

Theoretical considerations. Viscous boundary layers: When a particle settles at constant or terminal velocity, $U$, the gravitational force is exactly balanced by the total drag forces, created by pressure and shear at the aggregate-water interface (Schlichting 1987), thus:

$$
V\left(\rho_{\mathrm{a}}-\rho_{\mathrm{w}}\right) g=C_{\mathrm{D}} A \rho_{\mathrm{w}} U^{2}
$$

where $V$ is the volume of the aggregate in $\mathrm{cm}^{3}, \rho_{\mathrm{a}}$ is the density of the aggregate and $\rho_{w}$ is the density of the water in $\mathrm{g} \mathrm{cm}^{-3}, g$ is the gravitational acceleration of $980 \mathrm{~cm} \mathrm{~s}^{-2}, C_{D}$ is the drag coefficient, $A$ is the maximum cross-sectional area in $\mathrm{cm}^{2}$, and $U$ is the settling velocity in $\mathrm{cm} \mathrm{s}^{-1}$.

The drag forces are dependent on inertial and viscous forces acting at the aggregate-water interface. The relative importance of inertial and viscous forces acting on a sinking aggregate is described by the Reynolds number, Re (White 1974):

$$
\operatorname{Re}=\frac{U d_{0}}{v}
$$

where $U$ is the sinking velocity, $d_{0}$ is the sphere diameter and $v$ is the kinematic viscosity of the fluid.

Sinking aggregates are surrounded by a viscous boundary layer with strong velocity gradients of the moving water as the advection is directed by pressure gradients and skin friction at the aggregate-water interface. For impermeable spheres sinking at low Reynolds numbers, the velocity distribution in the viscous boundary layer is described by creeping flow (White 1974, Berg 1983):

$$
\begin{aligned}
& v_{\mathrm{r}}=v_{\max } \cos \theta\left(1-\frac{3 r_{0}}{2 r}+\frac{r_{0}{ }^{3}}{2 r^{3}}\right) \\
& v_{\theta}=-v_{\max } \sin \theta\left(1-\frac{3 r_{0}}{4 r}-\frac{r_{0}^{3}}{4 r^{3}}\right)
\end{aligned}
$$

where $v_{r}$ is the radial component and $v_{\theta}$ is the zenith component of the velocity of the water at the zenith angle $\theta_{i} r_{0}$ is the radius of the aggregate, $r$ is the radial distance from the center of the aggregate, and $r>r_{0}$. The formula is strictly valid only for $\mathrm{Re} \ll 1$, but it has been shown to be accurate up to $R e \approx 1$ (White 1974).

For a sphere suspended in a parallel, uniform flow or sinking at a low Reynolds number ( $\operatorname{Re} \leq 1$ ), the dynamic pressure is highest on the lower side (upstream) where the flow is decelerated due to the presence of the aggregate, and it is lowest on the upper side (downstream) where the flow is accelerated to the free-stream velocity. The difference in dynamic pressure between the water moving around an aggregate and the free-stream velocity is described by (White 1974, Schlichting 1987):

$$
\Delta p=\frac{3 \mu r_{0} U}{2 r^{2}} \cos \theta
$$

where $\Delta p$ is the pressure difference, $\mu$ is the dynamic viscosity, $U$ is the sinking velocity of the aggregate or the free-stream velocity of the water, and $r>r_{0}$. The pressure at the lower surface of a sinking aggregate, i.e. where $r=r_{0}$, relative to that of the free-stream velocity increases proportional to the sinking velocity of the aggregate and the dynamic viscosity of the water, whereas it is inversely proportional to the aggregate radius. The pressure difference between the water moving in the vicinity of an aggregate and water with the free-stream velocity decreases with the square of the distance from the aggregate surface.

Diffusive boundary layers: Water in the vicinity of an impermeable aggregate is very slowly exchanged due to the drag forces, i.e. skin friction and pressure, acting at the aggregate-water interface. Molecular diffusion can, however, occur freely and it is an efficient process of mass transfer over small distances. Diffusive boundary layers (DBL) with concentration gradients of solutes develop at small scales and at interfaces where the molecular diffusion time for the solute is faster than the time at which the water with its dissolved solutes can be replaced by advection.

The diffusive flux per unit surface area of a given solute through the DBL in a radial diffusion geometry is (Crank 1975):

$$
J=-D \frac{\mathrm{d} C}{\mathrm{~d} r}
$$

where $J$ is the flux, $D$ is the diffusion coefficient, and $\mathrm{d} C / \mathrm{d} r$ is the radial concentration gradient of the chemical solute.

The effective DBL thickness, $\delta_{\text {eff }}$, can be determined by linearly extrapolating the concentration gradient exactly at the aggregate surface to the radial distance at which it reaches the bulk water concentration:

$$
J=-D \frac{C_{\infty}-C_{0}}{\delta_{\text {eff }}}
$$


where $C_{x}$ is the bulk water concentration and $C_{0}$ is the concentration at the surface. It should be noted that such an extrapolation yields an equivalent flux of solute as described by Eq. (5).

The DBL thickness, as determined by Eq. (6), is directly related to the Sherwood number, Sh, for mass transfer in a sphere. The Sherwood number describes the relative increase in mass transfer due to advection relative to that of pure molecular diffusion. For an impermeable sphere, Sh equals the ratio of the sphere radius to its DBL thickness as determined by Eq. (6) (Sherwood et al. 1975):

$$
\mathrm{Sh}=\frac{r_{0}}{\delta_{\text {eft }}}
$$

where $r_{0}$ is the sphere radius. The Sherwood number is 1 when mass transfer occurs only by molecular diffusion. The Sherwood number increases as the DBL decreases due to flow. The total area-integrated flux of solutes per unit time, $Q_{t}$ due to advection and diffusion acting simultaneously around a sinking sphere is described by:

$$
Q_{t}=-\operatorname{Sh} 4 \pi r_{0} D\left(C_{x}-C_{0}\right)
$$

The Sherwood number is a function of the Peclet number, Pe (White 1974):

$$
\mathrm{Pe}=\frac{U d_{0}}{D}
$$

For $0.01<\mathrm{Pe}<5000$, in a uniform flow the Sherwood number has been described by (Clift et al. 1978, cf. Karp-Boss et al. 1996):

$$
\mathrm{Sh}=\frac{1}{2}\left[1+(1+\mathrm{Pe})^{1 / 3}\right]
$$

Diffusion coefficients for nutrients and gasses, e.g. $\mathrm{O}_{2}$ and $\mathrm{CO}_{2}$, are dependent on temperature, and in seawater they are on the order of $3 \times 10^{-6}$ to $2.5 \times 10^{-5}$ $\mathrm{cm}^{2} \mathrm{~s}^{-1}$ (Broecker \& Peng 1974, Li \& Gregory 1974). The diffusion coefficient for oxygen in sea water in the environmentally relevant temperature range is $1.22 \times$ $10^{-5}\left(4^{\circ} \mathrm{C}\right)$ to $2.26 \times 10^{-5} \mathrm{~cm}^{2} \mathrm{~s}^{-1}\left(25^{\circ} \mathrm{C}\right)$ (Broecker \& Peng 1974). Eq. (10) should therefore be valid for mass transfer of oxygen in 0.5 to $5 \mathrm{~mm}$ large marine aggregates with sinking velocities from 0.001 to $400 \mathrm{~m} \mathrm{~d}^{-1}$. These ranges comprise the majority of naturally occurring aggregates.

Empirical measurements. To create a parallel, nonturbulent, uniform flow in which an aggregate can be stabilized in suspension, a net was distended in a circular pipe with flowing water from below (Fig. 1). A nylon stocking (mesh size: 100 to $300 \mu \mathrm{m}$ ) was distended between the ends of 2 Plexiglas tubes (each $5 \mathrm{~cm}$ in diameter and a length of $5 \mathrm{~cm}$ ), which were then glued together with medical silicone adhesive.

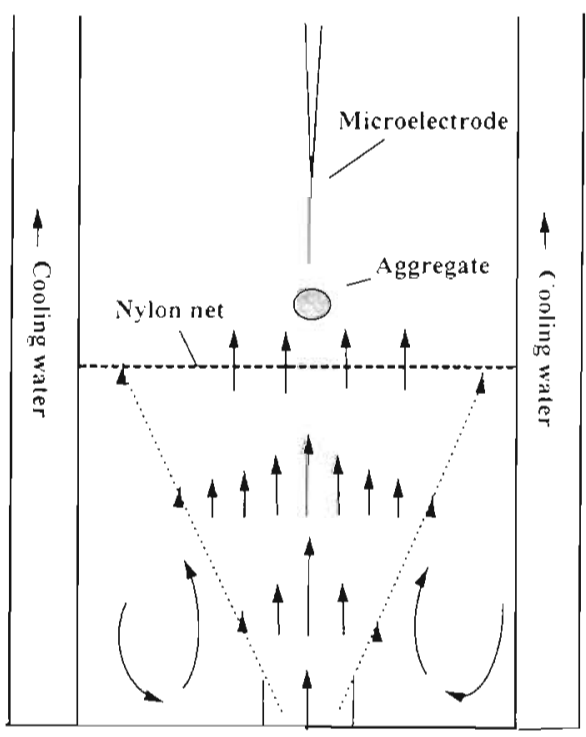

Fig. 1 The flow system. A net was distended between the ends of 2 circular tubes of equivalent diameter in order to create a parallel, uniform flow to balance the sinking velocity of individual aggregates above the net

The upper part of the flow chamber had 4 opposing outlets to make a symmetrical overflow back to the reservoir. A nylon stocking was used because it is easy to make a plane surface with this elastic net, it is easy to remove air bubbles mechanically beneath the surface of the net, and microelectrodes do not break if they penetrate the nylon stocking. In addition, a nylon stocking does not collect as many particles as a plankton net does, since its porosity is higher, whereas particles trapped in a plankton net tend to cause biofilm development with subsequent formation of oxygen gradients around the net (authors' unpubl. data).

The chamber was positioned in an outer casing or directly in an aquarium with filtered (pore size: $10 \mu \mathrm{m}$ ) water under temperature control. Water was pumped through a tubing outside the chamber up to a level above that of the overflow level of the chamber. It was here adjusted by a needle valve and fell by gravitation at atmospheric pressure through tubing connected to the inlet of the chamber. This created a homogenous flow through the chamber. The inlet of the chamber was $1 \mathrm{~cm}$ wide and positioned $3 \mathrm{~cm}$ under the net. The flow was adjusted so that the aggregate to be studied was suspended 0.5 to $1 \mathrm{~mm}$ above the net. The mean flow velocity was determined from the volume of water flowing through the chamber per unit time divided by the cross-sectional area of the chamber.

The flow field above the net was determined by adding neutrally buoyant pollen grains (Lycopodium sp. $27 \mu \mathrm{m}$ diameter) to the recirculating seawater. The pollen grains were sonicated in sea water prior to addition. The path of individual pollen grains was observed 

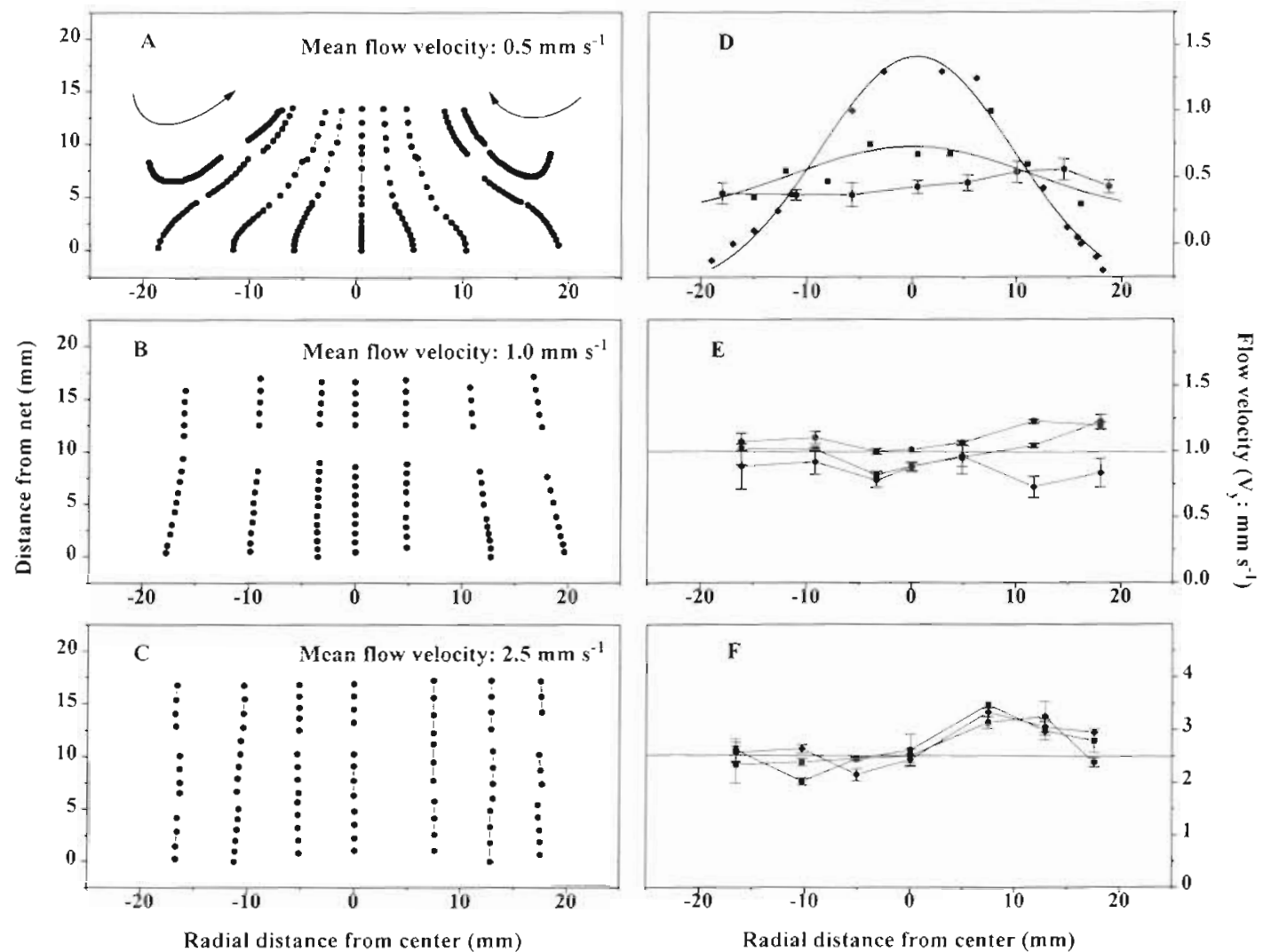

Fig. 2. Path of individual pollen grains (stream lines) shown at mean flow velocities of (A) $0.5 \mathrm{~mm} \mathrm{~s}^{-1}$ and (B) $1.0 \mathrm{~mm} \mathrm{~s}^{-1}$ at time intervals of $1 \mathrm{~s}$, and (C) $2.5 \mathrm{~mm} \mathrm{~s}^{-1}$ at time intervals of $0.5 \mathrm{~s}$. Corresponding velocity profiles in the vertical direction ( $\mathrm{V}$ ) across

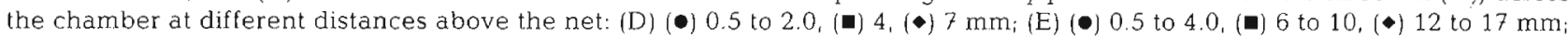
(F) $(\bullet) 0.5$ to 5 , ( 7 to $10,(\bullet) 12$ to $17 \mathrm{~mm}$

and measured through video recordings by a $\mathrm{CCD}$ camera equipped with a $135 \mathrm{~mm}$ zoom-macrolens (Nikon). The measurements were made at $18^{\circ} \mathrm{C}$.

Aggregates were made from a non-axenic diatom culture (Thalassirosira notula) originally isolated from the North Sea. It was grown at $15^{\circ} \mathrm{C}$ in a $12: 12 \mathrm{~h}$ light-dark cycle in North Sea water enriched with Guillard (F/20) medium (Guillard \& Ryther 1962). Diatom aggregates with Noctiluca sp. grown on a mixture of diatoms were made on a slowly rotating plankton wheel. Detritus aggregates were made from the detritus from a zooplankton culture, Acartia tonsa, grown on Rhodomonas baltica. Aggregates of diatoms or detritus were made in roller tanks (Shanks \& Edmonson 1989). Individual aggregates were transferred to the flow system with a wide-bore pipette.

Measurements of oxygen and photosynthesis in diatom aggregates were made using a Clark-type microelectrode (Revsbech 1989), which was inserted from above. The sensing tip was $4 \mu \mathrm{m}$ wide and the $90 \%$ response time was $0.2 \mathrm{~s}$. The stirring sensitivity was $<0.5 \%$. The oxygen microelectrode was calibrated in air- saturated and $\mathrm{N}_{2}$-flushed sea water. The electrode signal was measured using a picoamperemeter connected to a computer-based data acquisition system with a datacollection frequency of $510 \mathrm{~Hz}$ (LabVIEW 2, National Instruments). Gross photosynthesis was measured using the light-dark shift technique (Revsbech et al. 1981) from the initial decrease in oxygen concentration during the first $1.0 \mathrm{~s}$ of darkness. The position of the aggregate surface was determined by slowly advancing the microelectrode towards the aggregate until it visibly touched the upper surface as observed under a dissection microscope. The optical resolution was optimal when the flow chamber was submersed in the aquarium, and the microelectrode and the aggregate surface could easily be observed under the dissection microscope at 25 to 50 times magnification. The microelectrode measurements were made at the temperature at which the cultures had been grown. The light source was a $150 \mathrm{~W}$ halogen fiberoptic lamp equipped with an infra-red cut-off filter (Schott, Kl 1500). The light intensity was measured inside the chamber with an underwater scalar irradiance sensor (Biospherical Instruments, QLS 100). 
The analytical solutions for spherical diffusion were fitted to the measured oxygen distribution in the DBL by applying the solver routine of the spreadsheet program Excel 4.0 (Microsoft) to determine the effective DBL as earlier described (Ploug et al. 1997).

\section{RESULTS}

\section{The flow system}

The flow field in the chamber was measured from 0 to $17 \mathrm{~mm}$ above the net and laterally across the net at a spatial resolution of $<0.25 \mathrm{~mm}$. This was done for mean flow velocities of $0.5,1.0$, and $2.5 \mathrm{~mm} \mathrm{~s}^{-1}$, corresponding to 44,88 , and $220 \mathrm{~m} \mathrm{~d}^{-1}$, respectively. The paths of individual pollen grains, i.e. the stream lines, and the flow velocities in the vertical direction $\left(V_{y}\right)$ at different heights above the net are shown in Fig. 2. Turbulent eddies could not be detected above the net at any flow velocity. At all flow velocities, the mean velocity at distances from 0.5 up to $4 \mathrm{~mm}$ or more above the net corresponded to the measured flow velocity. This implies that the net provided a resistance which caused an even flow above the net. None of the flow profiles corresponded to a fully developed laminar flow, which is a parabolic velocity profile with a central maximum velocity 2 -fold higher compared to the mean flow velocity and a zero velocity at the wall.

At mean flow velocities of 1 to $2.5 \mathrm{~mm} \mathrm{~s}^{-1}$, the flow velocity across the chamber remained constant within $20 \%$ up to a distance of $17 \mathrm{~mm}$ above the net (Fig. $2 \mathrm{E}$, F). At a flow velocity of $0.5 \mathrm{~mm} \mathrm{~s}^{-1}$, a slowly moving back-flow was observed along the walls (Fig. 2A, D). This downward directed back-flow was moving with a velocity of $0.1 \mathrm{~mm} \mathrm{~s}^{-1}$ at distances $17 \mathrm{~mm}$ from the center and $7 \mathrm{~mm}$ above the net, and it was presumably created as the flow is directed towards the periphery at the outlets in the top of the chamber. Due to this vortex formation, the flow was forced from the walls to the center of the chamber, whereby the central velocity increased nearly 3 -fold $7 \mathrm{~mm}$ above the net as compared to the velocity $2 \mathrm{~mm}$ above the net.

A decrease in flow velocity of the pollen grains occurred from 0 to $0.5 \mathrm{~mm}$ distance above the net, due to the presence of microjets and microwakes produced by the net (Fig. 3). The mean distance between each measured jet was $0.25 \mathrm{~mm}$ (Fig 3A). No turbulence was observed above the net at flow velocities up to $2.5 \mathrm{~mm} \mathrm{~s}^{-1}$. The flow velocity in the microjets $0.1 \mathrm{~mm}$ above the net was 3 -fold higher than the mean flow through the chamber, when this was $0.6 \mathrm{~mm} \mathrm{~s}^{-1}$, whereas it was only 1.3 -fold higher in the jets $0.1 \mathrm{~mm}$ above the net as compared to the mean flow velocity, when this was $2.5 \mathrm{~mm} \mathrm{~s}^{-1}$. At $0.5 \mathrm{~mm}$ above the net, the
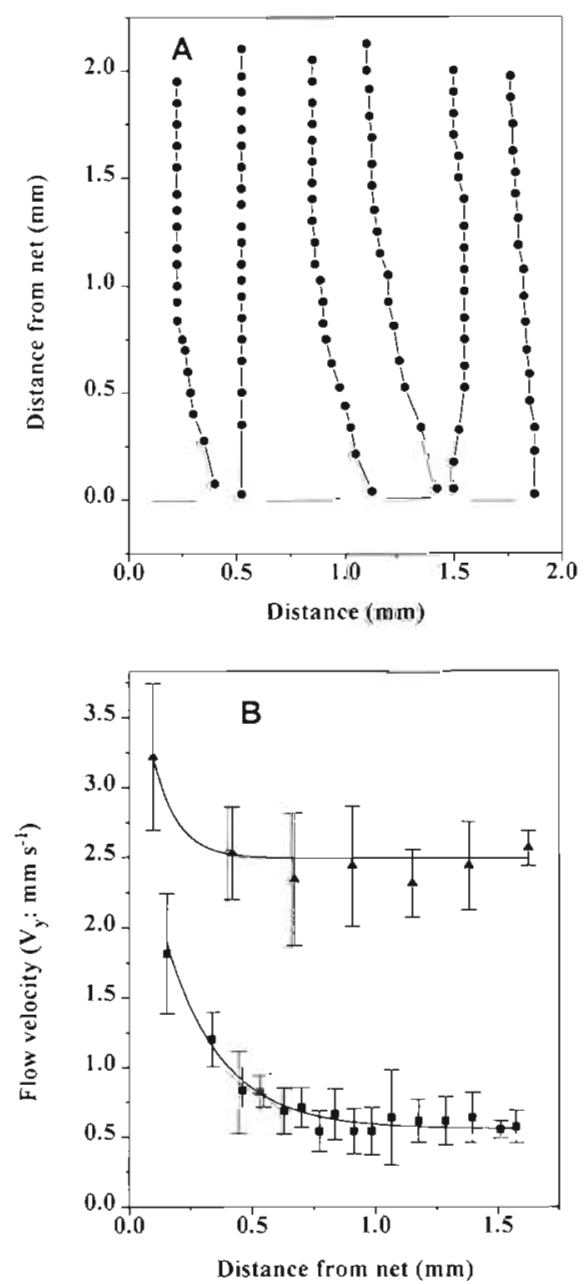

Fig. 3. (A) Paths of individual pollen grains (stream lines) above the net shown at time intervals of $0.1 \mathrm{~s}$ for a mean flow velocity of $1.0 \mathrm{~mm} \mathrm{~s}^{-1}$ at high spatial resolution. (B) Mean velocity in the vertical direction $\left(V_{y}\right)$ of individual pollen grains above the net shown at a mean flow velocity of 0.5 (ש) and $2.5 \mathrm{~mm} \mathrm{~s}^{-1}(\mathbf{4})$

flow velocity of each jet corresponded to the mean flow velocity through the chamber, whereby the water flow must be uniform at a microscale across the chamber.

\section{Mass transfer in aggregates}

The water passing 2.0 to $2.5 \mathrm{~mm}$ large aggregates composed of Noctiluca sp. and diatoms was more strongly influenced by the drag of the aggregate than by the microscale velocity gradients immediately above the net (Fig. 4A). The boundary layer flow created by the drag from an aggregate with a short axis of $2.0 \mathrm{~mm}$ and a long axis of $2.5 \mathrm{~mm}$ showed strong gradients in flow velocity up to $2.5 \mathrm{~mm}$ from the aggregate surface along the horizontal axis perpendicular to the aggregate (Fig. 4B). The aggregate was kept in sus- 

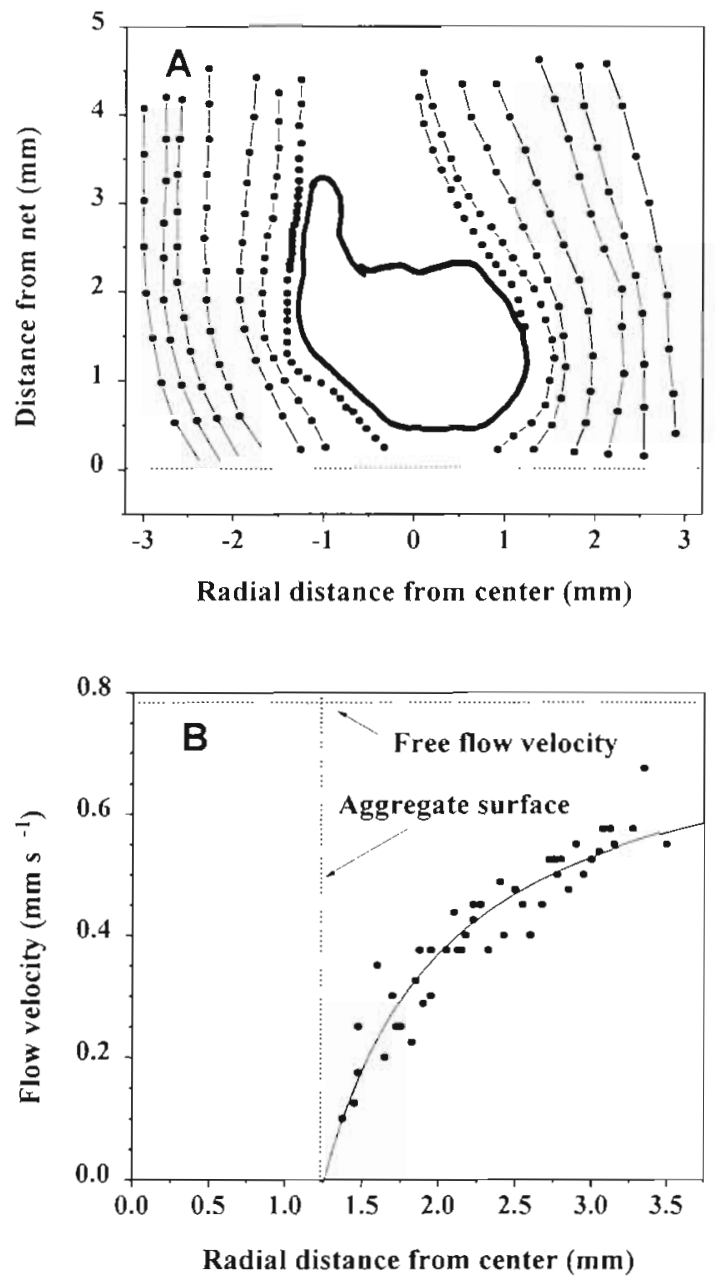

Fig. 4. (A) Paths of individual pollen grains in the viscous boundary layer of a Noctiluca sp. diatom aggregate shown with $1 \mathrm{~s}$ intervals. (B) Velocity profile along the horizontal axis from the center of the aggregate as measured ( $)$ during 3 series of measurement in the viscous boundary layer and modeled (curve) from Stokes' creeping flow

pension by a mean flow velocity through the chamber of $0.7 \mathrm{~mm} \mathrm{~s}^{-1}\left(60 \mathrm{~m} \mathrm{~d}^{-1}\right)$. The kinematic viscosity of the sea water was $1.1 \times 10^{-2}\left(18^{\circ} \mathrm{C}\right.$ and $\left.34 \%\right)$. Re of the aggregate was 1.6, calculated using Eq. (2).

The measured flow velocities along different axes ( $45^{\circ}$ to $135^{\circ}$ zenith angle) of the aggregate could be fitted to Stokes' (creeping) flow for impermeable spheres with a sinking velocity of 0.71 to $0.79 \mathrm{~mm} \mathrm{~s}^{-1}$ (Origin 3.0, MicroCalc Software, Inc.). The measured values for 3 series of measurements and the modeled curve (cf. Eq. 3) along the horizontal axis perpendicular to the flow $\left(90^{\circ}\right)$ relative to the axis parallel to the incident flow are shown in Fig $4 \mathrm{~B}$. According to theory (Eq. 3), the viscous boundary layer surrounding a sinking aggregate with a low Reynolds number extends to a distance 9 radii from the center, where it reaches a velocity which is $90 \%$ of the free-flow velocity. The measured mean flow velocity was $0.7 \mathrm{~mm}^{-1}$. The measured and fitted value of the free-stream velocity agreed within $11 \%$.

The distribution of oxygen in a diatom aggregate of a similar size to that shown in Fig. 4 , but with a sinking velocity of $0.44 \mathrm{~mm} \mathrm{~s}^{-1}\left(38 \mathrm{~m} \mathrm{~d}^{-1}\right)$, was measured by the use of oxygen microelectrodes in darkness and at a light intensity of $250 \mu \mathrm{E} \mathrm{m}^{-2} \mathrm{~s}^{-1}$, at which photosynthesis was saturated (Fig. 5). In the light, the oxygen concentration in the center of the aggregate was increased by $85 \%$ compared to the bulk water phase, whereas it decreased to $30 \%$ of the bulk water phase in the dark. The profiles were highly reproducible, as shown by the 3 series of measurements. The $\delta_{\text {eff }}$ upstream was $0.5 \mathrm{~mm}$ and the $\delta_{\text {ell }}$ downstream was $0.6 \mathrm{~mm}$. Re was 1.0. The $\mathrm{O}_{2}$ gradients indicate that mass transfer at the aggregate-water interface mainly occurred by molecular diffusion. The diffusion coefficient of oxygen in sea water $\left(34 \%\right.$ ) at $15^{\circ} \mathrm{C}$ is $1.88 \times 10^{-5} \mathrm{~cm}^{2} \mathrm{~s}^{-1}$ (Broecker \& Peng 1974). The Peclet number for oxygen transfer was, thus, 550 (cf. Eq. 9), and the Sherwood number 4.6 (cf. Eq. 10), which corresponds to a theoretical average DBL thickness of $0.27 \mathrm{~mm}$, assuming spherical symmetry of the aggregate (cf. Eq. 7). The flux of oxygen was calculated according to Eqs. (5) \& (6). In the dark, the fluxes of oxygen across the aggregate-water interface were 127 and $116 \mathrm{nmol} \mathrm{O}_{2} \mathrm{~cm}^{-2} \mathrm{~h}^{-1}$ upstream and downstream, respectively. In the light, the fluxes were 188 and $185 \mathrm{nmol} \mathrm{O}_{2} \mathrm{~cm}^{-2} \mathrm{~h}^{-1}$ upstream and downstream, respectively. The flux upstream was, therefore, $9.4 \%$ higher upstream than downstream in

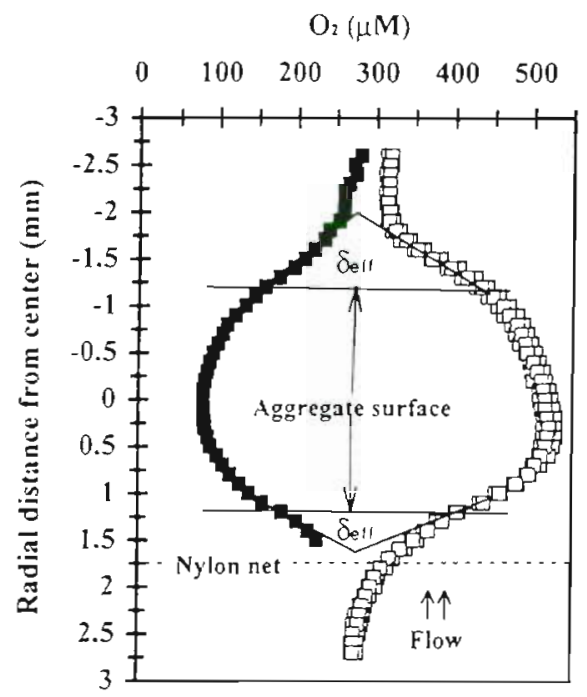

Fig. 5. Vertical, radial distribution of oxygen measured in the light (a) at $250 \mu \mathrm{E} \mathrm{m}^{-2} \mathrm{~s}^{-1}$ (3 series of measurements are shown) and in the dark (-). $\delta_{\text {eif. }}$ was determined from extrapolation of the oxygen gradient at the aggregate surface to the concentration in the bulk water phase 
darkness, whereas there was no difference in fluxes upstream and downstream in the light.

Gradients of oxygen were mapped in 2 dimensions from $\mathrm{O}_{2}$ profiles measured at $0.1 \mathrm{~mm}$ depth increments spaced laterally $1.0 \mathrm{~mm}$ apart at saturating light intensity (Fig. 6). For these measurements a larger diatom aggregate was chosen, with a long axis of $5 \mathrm{~mm}$ and a short axis of $2.5 \mathrm{~mm}$, in order to better analyze the boundary layer thickness around the aggregate. As before, the flow velocity was adjusted to keep the aggregate in suspension. The mean flow velocity was $0.45 \mathrm{~mm} \mathrm{~s}^{-1}$. Then the aggregate was fixed at its position by the use of 2 entomological needles fixed in the net to prevent any movement of the aggregate during the measurements. From these measurements, isopleths of oxygen concentration were calculated (Winsurfer, minimum curvature, max error: 0.001). Gradients in oxygen concentration were detectable at $1 \mathrm{~mm}$ distance from the aggregate surface, which indicates that the radial transport of solutes mainly occurred by molecular diffusion. $\delta_{\text {eff }}$ was $0.38 \mathrm{~mm}$ upstream (below) of the aggregate, $0.85 \mathrm{~mm}$ along the sides and $1.0 \mathrm{~mm}$ downstream of the aggregate.

In a near-spherical, $2.4 \mathrm{~mm}$ diameter diatom aggregate, the radial distribution of photosynthesis was measured in the light at $250 \mu \mathrm{E} \mathrm{m}{ }^{2} \mathrm{~s}$ ', and the gradients of oxygen were measured at the same light intensity and in the dark (Fig. 7). The aggregate had a sinking velocity of $63 \mathrm{~m} \mathrm{~d}^{-1}$ and $\operatorname{Re}$ was 1.3. Pe for the aggregate was 900 , and Sh was accordingly 5.3 , which corresponds to a DBL thickness of $0.24 \mathrm{~mm}$ averaged over the whole sphere. The measured boundary layer thickness was 0.17 and $0.42 \mathrm{~mm}$ upstream and downstream, respectively, or $0.30 \mathrm{~mm}$ on average.

Photosynthesis was highest at the aggregate surface and substantially lower in the center, and the oxygen concentration varied between 47 and $190 \%$ of air saturation, when measured in the dark and light, respectively. The net fluxes of oxygen in the light were 142 and $154 \mathrm{nmol} \mathrm{O}_{2} \mathrm{~cm}^{-2} \mathrm{~h}^{-1}$ upstream and downstream, respectively, and, hence, $8 \%$ lower upstream compared with downstream. The respiration rate in the dark was high, and the fluxes of oxygen across the aggregate surface were 116 and $110 \mathrm{nmol} \mathrm{O} \mathrm{cm}^{-2} \mathrm{~h}^{-1}$ upstream and downstream, respectively. The net photosynthesis and dark respiration of the whole aggregate were calculated from the mean of the measured upstream and downstream fluxes (cf. Eq. 8). The net photosynthesis was $28 \mathrm{nmol} \mathrm{O}_{2} \mathrm{~h}^{-1}$, and the dark respiration was $20 \mathrm{nmol} \mathrm{O}_{2} \mathrm{~h}^{-1}$. The dark respiration, thus, comprised $42 \%$ of the gross photosynthesis of $48 \mathrm{nmol} \mathrm{O}_{2} \mathrm{~h}^{-1}$, which was calculated as net photosynthesis plus dark respiration.

The volumetric gross photosynthesis was measured using the light-dark shift technique. The gross photo-

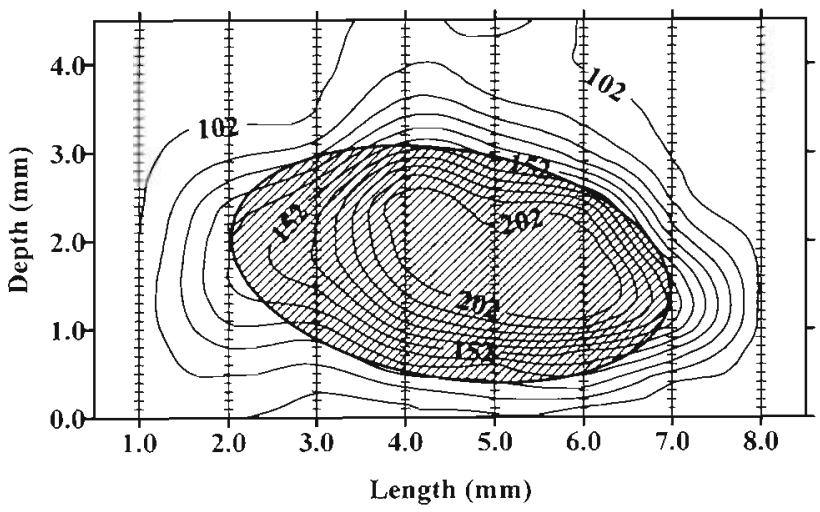

Fig. 6. Isopleths of oxygen concentration ( $\%$ of air saturation) inside an aggregate (shaded area) and in the surrounding water. (+) Measuring points

synthesis was integrated by regarding the aggregate as an array of concentric shells of $0.1 \mathrm{~mm}$ thickness, where the volume of each shell is described by $4 / 3 \pi\left[(r+0.1)^{3}\right.$ $\left.-r^{3}\right]$. The volume-integrated photosynthesis measured using the light-dark shift technique yielded a gross photosynthesis of $127 \mathrm{nmol} \mathrm{O} \mathrm{O}^{-1}$. The gross photosynthesis was, thus, $264 \%$ of that determined from the net $\mathrm{O}_{2}$ production in the light plus the respiration in the dark. This discrepancy was probably due to an underestimation of the true light respiration, which was accordingly 5 -fold higher than the dark respiration. The respiration in light cannot be detected by flux measurements alone, because part of the oxygen produced through photosynthesis is also respired within the aggregate.

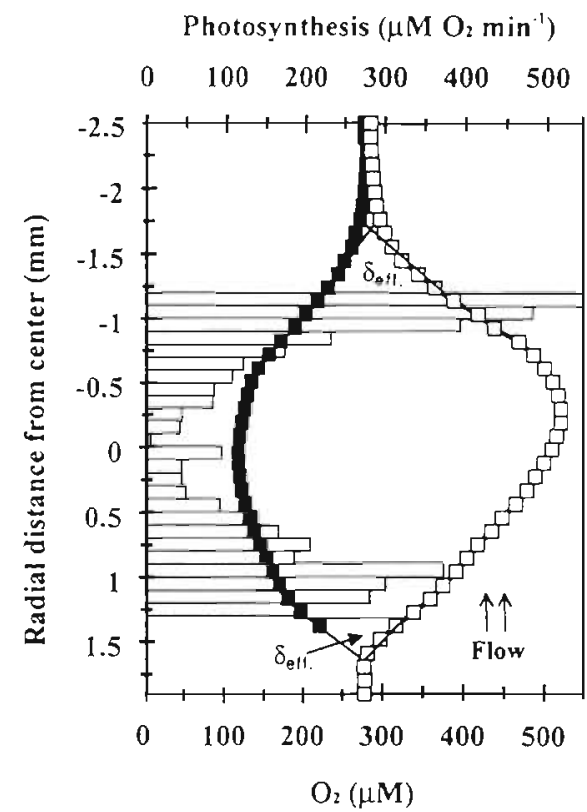

Fig. 7. Radial distribution of oxygen, in the light ( $\square$ ) and in the dark (-), and photosynthesis (bars). Each profile represents the mean of 3 series of measurements 


\section{Diffusion in flow}

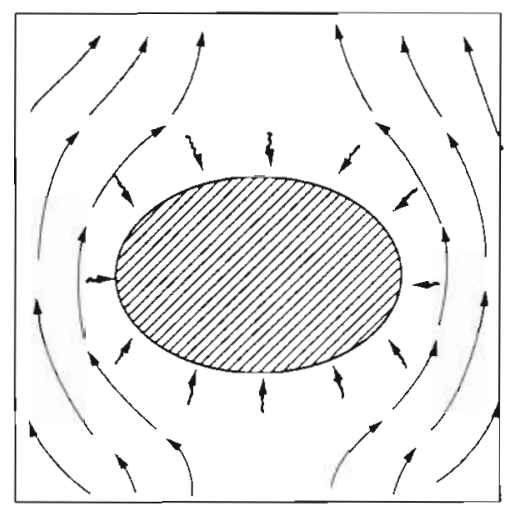

$\mathrm{O}_{2}$ (in \% of air sat.)

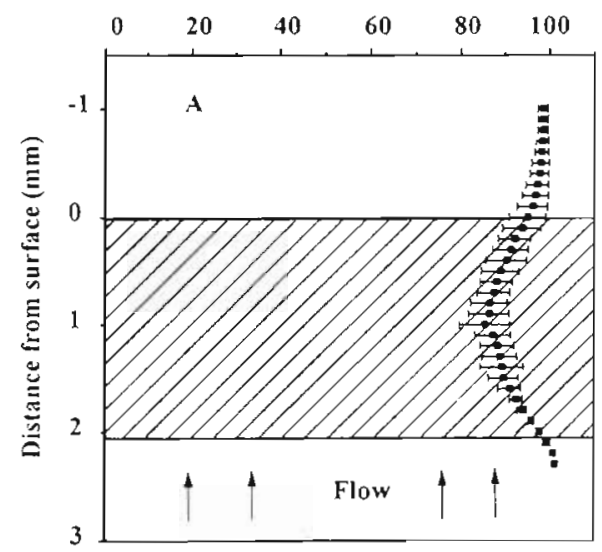

Diffusion at a solid surface

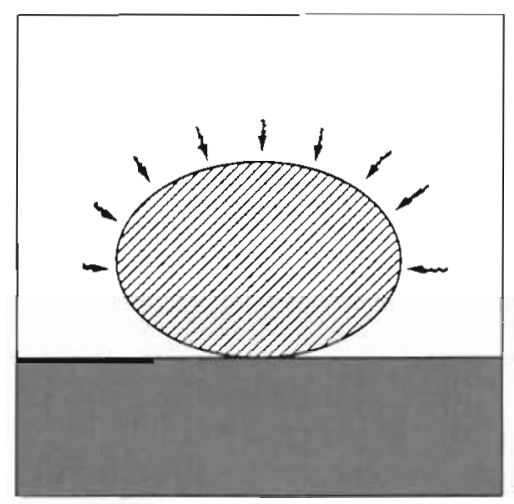

$\mathrm{O}_{2}$ (in \% of air sat.)

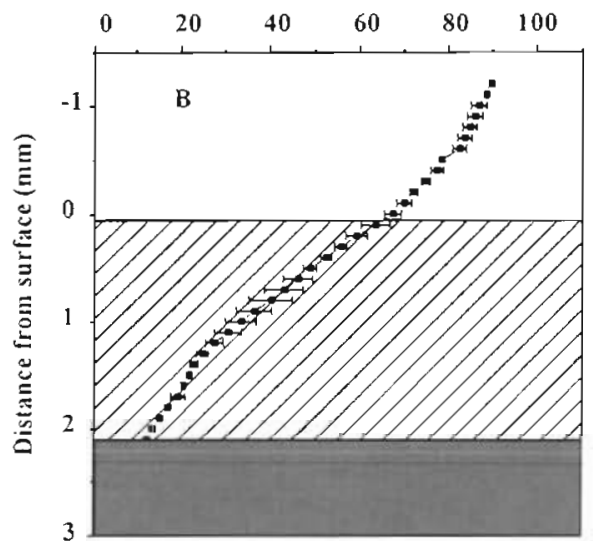

Fig. 8. Oxygen distributions in (A) a sinking aggregate and (B) when it is sitting on a solid surface. Each profile represents the mean $( \pm S D)$ of 3 series of measurements

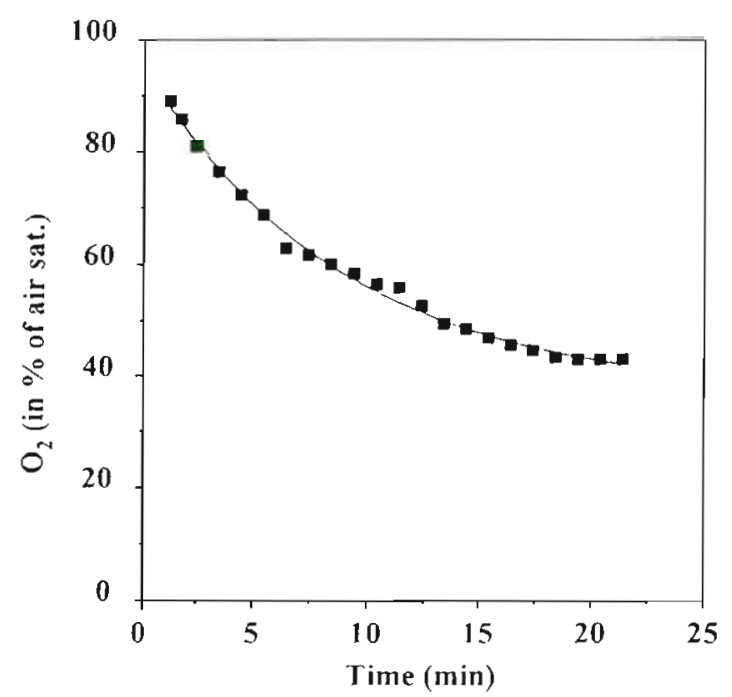

Fig. 9. Oxygen concentration measured at a fixed position $0.2 \mathrm{~mm}$ inside the aggregate immediately after the aggregate had been transferred onto a solid surface $(t=0)$
The oxygen gradients were analyzed in sinking detritus aggregates in the flow system and when the aggregates were sitting on a solid surface. An example is shown in Fig. 8. The oxygen gradients of the aggregate were first analyzed during sinking, after which the aggregate was transferred into a cuvette $\left(1 \mathrm{~cm}^{2}\right)$, in which it sat at the bottom during the measurements. The cross-sectional area of single aggregates was $<10 \%$ of that of the cuvette. During sinking, the oxygen concentration was $86 \%$ of air saturation inside the aggregate due to microbial respiration (Fig. 8A). The shortest axis of this aggregate was $2.1 \mathrm{~mm}$ and the longest axis was $3.4 \mathrm{~mm}$, and its sinking velocity was $120 \mathrm{~m} \mathrm{~d}^{-1}$. Re was 4, Pe was 2200, and Sh was 7.0, which corresponds to an average DBL thickness of $0.19 \mathrm{~mm}$. The measured DBL thickness was $0.09 \mathrm{~mm}$ upstream and $0.45 \mathrm{~mm}$ downstream, and the fluxes of oxygen were 23.6 and $20.3 \mathrm{nmol} \mathrm{O}_{2} \mathrm{~cm}^{-2} \mathrm{~h}^{-1}$ upstream and downstream, respectively. The gradients changed immediately after the aggregates were transferred onto the surface. The 
oxygen concentration at a fixed position $0.2 \mathrm{~mm}$ within the aggregate after it had been transferred onto the solid surface is shown in Fig. 9. About $50 \%$ of the total decrease in oxygen concentration occurred within the first 5 min, and a new steady state of the gradients in the aggregate was established after ca $15 \mathrm{~min}$. The depth distribution of oxygen was then similar to that measured in sediments since oxygen could not diffuse into the aggregate from below (Fig. 8B). The oxygen concentration was only $10 \%$ of air saturation at the lower surface of the aggregate next to the solid surface. The DBL thickness was $1 \mathrm{~mm}$ and the 1 -dimensional diffusive flux at the upper surface of the aggregates was $43 \mathrm{nmol} \mathrm{O}_{2} \mathrm{~cm}^{-2} \mathrm{~h}^{-1}$. When the aggregate was sitting on a surface the flux across the upper surface area was, thus, equal to the sum of fluxes across the surface areas upstream and downstream during sinking. This difference can be explained by the fact that only ca $50 \%$ of the aggregates' surface area was exposed to the surrounding water when sitting on a solid surface. The oxygen being consumed in the lower part of the aggregates was transferred through the aggregate from the upper surface with contaminant oxygen consumption. A microenvironment with significantly different oxygen concentrations was, consequently, created when an aggregate was sitting on a surface compared to when it was sinking.

\section{DISCUSSION}

The oxygen and $\mathrm{pH}$ microenvironment of marine snow has already been studied by the use of microelectrodes (Alldredge \& Cohen 1987). In that study, the marine snow particles were placed in a small cone made of a plankton net and turbulence was induced by a pipette producing air bubbles from below. In the present study, a flow of seawater from below stabilized the aggregates in suspension. This arrangement is equivalent to an aggregate sinking down through the water column at a velocity equal to the water flow. To stabilize a sinking aggregate in a suspended phase, its sinking velocity must be balanced by an upward directed parallel uniform flow. This was created by distending a net in a circular pipe. During microelectrode movements (50 to $100 \mu \mathrm{m}$ step size), sometimes the electrodes initially pushed the aggregate closer to the net. The water flow then pushed the aggregate back to its original position above the net as observed through the dissection microscope. The exact position at which the aggregates stabilized above the net may therefore be determined by the dynamic pressure distribution surrounding an aggregate sinking at a low Reynolds number relative to the dynamic pressure of the flow velocity around or within the net (cf. Eq. 4).
The flow field within and around sinking aggregates has been modeled in theoretical studies of scavenging rates and mass transfer in sinking aggregates (Logan \& Hunt 1987, Logan \& Alldredge 1989, Stolzenbach 1993). Noctiluca $\mathrm{sp}$. is a heterotrophic dinoflagellate which feeds on diatoms in aggregates which scavenge smaller particles through sinking and turbulence (Kiørboe et al. 1998, Tiselius \& Kiørboe 1998). In the present study, the flow field around sinking aggregates of diatoms and Noctiluca sp. was directly measured (Fig, 4). The flow field around the aggregate sinking at $\operatorname{Re}=1.6$ agreed well with that predicted by Stokes' theory for creeping flow around impermeable spheres at $R e \leq 1$. Creeping flow is strictly defined only for $\operatorname{Re}<0.1$, but it has earlier been shown to be an accurate description of the flow around spheres sinking at $\operatorname{Re}=1$ (White 1974). A turbulent wake downstream created by large pressure gradients in the vicinity of a sinking aggregate cannot be expected until $\mathrm{Re} \approx 20$ (White 1974). The aggregate size or its sinking velocity should, accordingly, be ca 20 -fold larger before turbulence may occur in its wake during sinking (cf. Eq, 2),

This study demonstrates that DBLs develop at interfaces where the water movement is dominated by viscous forces and where the radial diffusion is fast compared to advection, which mainly occurs laterally during sinking. The average DBL thickness of a sphere is indirectly expressed by the Sherwood number, Sh. The Sherwood number describes the increase in total mass transfer due to flow relative to that of pure molecular diffusion, when the biological processes are diffusion limited and the sphere is impermeable to flow (Sherwood et al. 1975). It is, thus, dependent on the average DBL thickness surrounding a sphere of a given diameter, and it increases as the DBL thickness decreases due to flow. The DBL thicknesses around sinking aggregates were in good agreement with those predicted by the Sherwood number (cf. Eq. 10) for sinking spheres when Re was between 1 and 4 . The measured DBL thickness was thinner upstream compared with downstream. The DBL can be expected to be thinnest along the sides and the leading edge, where the shear is highest. Two-dimensional mapping of oxygen concentrations in a non-spherical aggregate with a short axis of $2.5 \mathrm{~mm}$ and a long axis of $5 \mathrm{~mm}$ showed strong gradients of oxygen extending to a distance of $1 \mathrm{~mm}$ from the surface along the sides of the aggregate (Fig. 6). The measured DBL thickness was thinnest upstream, thickest downstream, and of intermediate thickness along the sides. A partial explanation may be that the aggregates were not spherical. The longest axis of the aggregates was always oriented parallel to the flow, whereby the drag of the sinking aggregate is at its maximum (Berg 1983). Natural sink- 
ing aggregates appear to have a similar orientation as has been demonstrated in situ by Alldredge \& Gotschalk (1988).

The magnitude of concentration gradients in the DBL is dependent on the bulk water concentrations of the chemical species and their diffusion coefficients, the aggregate size and its DBL thickness, and the densities and biological activities of microorganisms within the aggregate (Ploug et al. 1997). Diffusion limitation of biological processes only occurs when the potential flux created by the activities of phytoplankton and microorganisms exceeds the maximim potential flux though the DBL. In the present study, the fluxes were up to $10 \%$ higher upstream and downstream, although the DBL thickness of aggregates was up to 5-fold thinner upstream compared with downstream due to flow (Fig. 8). When the same aggregate was sitting on a surface, the flux oxygen across its upper surface was equal to the sum of fluxes across its lower and upper surface during sinking. This result suggests that the aggregate was impermeable to flow, because the total diffusive flux remained unchanged during sinking. The fluxes were, thus, governed by the biological processes rather than by the DBL thickness, i.e. the respiration was not diffusion limited in this aggregate presumably due to a low half-saturation constant for oxygen respiration.

The microenvironments of aggregates and planktonic colonies of microalgae have previously been studied by the use of micro-and minielectrodes, and by addition of tetrazolium salts (Paerl \& Bebout 1988, Richardsson et al. 1988, Paerl et al. 1989, Lubbers et al. 1990, Shanks \& Reeder 1993). In these studies the aggregates or colonies were positioned on a solid surface, e.g. a petri dish or a microscope slide, during the measurements or observations through a microscope. Such an experimental approach can, however, lead to artificially steep gradients of oxygen and other solutes in the aggregates or colonies since the field of mass transfer is changed from the natural 3-dimensional diffusion field encountered in situ in the ocean to a diffusion field in which diffusion is limited by the solid surface (Fig. 8). In other experimental studies with radiotracers, e.g bacterial production measurements, several aggregates are often concentrated in a small volume of water to limit the amount of tracer used and to obtain a high signal from the aggregates compared to that of the surrounding water. Bacterial production rates on marine snow have often been surprisingly low (Simon et al. 1990, Smith et al. 1992). The present study shows that concentrating aggregates in a small volume or incubating just 1 aggregate while it is sitting on a surface leads to an increased diffusion distance whereby diffusion limitation of solutes from the surrounding water can easily occur within a few minutes
(Fig. 9). Energy limitation of the metabolic processes may occur in the aggregates if the increased diffusion distance also leads to anoxic conditions within a sample. The bacterial production rates in aggregates may, therefore, be underestimated in the ocean.

The oxygen distribution and fluxes of oxygen in the aggregate shown in Fig. 8 during sinking were similar to those measured in natural aggregates in the ocean (Ploug et al. in press); the oxygen distribution and the fluxes of oxygen when the aggregate was sitting on a solid surface were similar to those measured in coastal sediments (Gundersen \& Jorgensen 1991). Aggregates sinking into sediment traps can, therefore, undergo similar microenvironmental changes. With slightly higher respiration rates or larger sizes of aggregates, the aggregates may easily turn anoxic at the bottom of a sediment trap if the trap does not contain fixative

The $\mathrm{O}_{2}$ gracients and photosynthesis distribution shown in Fig. 7 are similar to measurements made in natural marine snow comprised of diatoms (Alldredge \& Cohen 1987). In both that study and the present study, photosynthesis was lower in the central parts of the aggregates, which may be due to light gradients inside the aggregate. Spectral light gradients due to shading have been demonstrated in cyanobacterial aggregates (Prufert-Bebout et al. 1993) by the use of a light microsensor (Lassen et al. 1992).

The oxygen consumption during the light was 5-fold higher than the dark respiration (Fig. 7). Enhanced oxygen consumption in light has also been demonstrated in cyanobacterial biofilms from sewage treatment plants (Kühl et al. 1996). Excretion of easily degradable carbohydrates during photosynthesis may enhance bacterial oxygen uptake in light. Diel cycle experiments on bacterial activity and primary production in the ocean have shown bacterial growth rates to be highest during the day and lowest at night, which indicates that bacterial growth is dependent on exudates from phytoplankton (Fuhrman et al. 1985, Herndl \& Malacic 1987). The enhanced respiration in light may also partly be due to photorespiration as the oxygen concentration inside the aggregate was highly supersaturated during photosynthesis and $\mathrm{CO}_{2}$ concentrations may then be low. Respiration in natural biofilms of diatoms has been shown to increase at high $\mathrm{O}_{2}$ : $\mathrm{CO}_{2}$ ratios during photosynthesis (Glud et al. 1992).

Direct measurements of viscous boundary layers with steep gradients in flow velocity leading to the formation of diffusive boundary layers are important in order to understand mass transfer, particle scavenging rates and conversion rates in sinking aggregates as well as for single free-living organisms, e.g. zooplankton. The presented experimental flow system provides a very simple tool for such studies. The flow system has been used to study the respiratory degradation process 
of sinking detritus aggregates (Ploug et al. 1997) and marine snow (Ploug et al. in press). A vertical flow system based on principles similar to those described in the present study was recently developed to observe behavior of zooplankton around sinking marine snow (Shanks \& del Carmen 1997, Shanks \& Walters 1997). The use of microsensors in the flow system allows direct measurements of diffusive boundary layers and the chemical microenvironment of freely sinking aggregates. Thus, the actual growth conditions and biological activities, e.g. photosynthesis and respiration, in sinking aggregates can now be studied at high spatial resolution.

Acknowledgements. Thanks are due to Anja Eggers and Gaby Eickert for constructing the microelectrodes and to Gerhard Kothe and Georg Herz for constructing a roller table. We also thank Volker Meyer for skilful assistance and construction of electronics. The data acquisition program was developed by Brad M. Bebout and Volker Meyer. Thomas Kiorboe Danish Institute for Fisheries and Marine Research, Charlottenlund, Denmark, is thanked for providing laboratory space and flow visualization equipment for flow measurements and for constructive comments. The Noctiluca sp. culture was kindly provided by Thomas Kiørboe. The diatom cultures were kindly provided by Ulf Riebesell and Christian Hamm, Alfred Wegener Institute for Polar and Marine Research, Bremerhaven, Germany. Claus Lundsgaard, Michael Olesen, and Lars Peter Nielsen are thanked for discussions in the initial stage of developing the flow system. This work was supported by the Danish Natural Science Research Council (J: 11-0557-1 to H.P.) and the Max Planck Society.

\section{LITERATURE CITED}

Alldredge AL, Cohen Y (1987) Can microscale chemical patches persist in the sea? Microelectrode study of marine snow and fecal pellets. Science 235:689-691

Alldredge AL, Gotschalk C (1988) In situ settling behavior of marine snow. Limnol Oceanogr 33(3):339-351

Alldredge AL, Passow U, Logan BE (1993) The abundance and significance of a class of large transparent organic particles in the ocean. Deep-Sea Res 40:1131-1140

Alldredge AL, Silver M (1988) Characteristics, dynamics and significance of marine snow. Prog Oceanogr 20:41-82

Berg HC (1983) Random walks in biology. Princeton University Press, Princeton

Broecker WS, Peng TH (1974) Gas exchange rates between air and sea. Tellus 26:21-35

Clift R, Grace JR, Weber ME (1978) Bubbles, drops and particles. Academic Press, New York

Crank J (1975) The mathematics of diffusion. Oxford University Press, Oxford

Fuhrman JA, Eppley RW, Hagström $\AA$, Azam F (1985) Diel variations in bacterioplankton, phytoplankton and related parameters in the Southern California Bight. Mar Ecol Prog Ser 27:9-20

Glud RN, Ramsing NB, Revsbech NP (1992) Photosynthesis and photosynthesis-coupled respiration in natural biofilms quantified with oxygen microsensors. J Phycol 28:51-60

Grossart HP, Berman T, Simon M, Pohlmann K (1998) Occurrence and microbial dynamics of macroscopic organic aggregates (lake snow) in Lake Kinneret, Israel, in fall. Aquat Microb Ecol 14:59-67

Grossart HP, Simon M (1993) Limnetic macroscopic organic aggregates (lake snow): occurrence, characteristics, and microbial dynamics in Lake Constance. Limnol Oceanogr 38:532-546

Guillard RRL, Ryther JH (1962) Studies of marine planktonic diatoms. l. Cyclotella nana (Hustedt) and Detonula confervacea (Cleve) Gran. Can J Microbiol 8:229-239

Gundersen JK, Jørgensen BB (1991) Fine-scale in situ measurements of oxygen distribution in marine sediments. Kiel Meeresforsch Sonderh 8:376-380

Herndl ( $J$, Malačič $V$ (1987) Impact of the pycnocline layer on bacterioplankton: diel and spatial variations in microbial parameters in the stratified water column of the Gulf of Trieste (Northern Adiatic Sea). Mar Ecol Prog Ser 38: 295-303

Karp-Boss L, Boss E, Jumar PA (1996) Nutrient fluxes to plankton osmotrophs in the presence of fluid motion. Oceanogr Mar Biol Annu Rev 34:71-107

Kiørboe T, Tiselius P, Mitchell-Innes B, Hansen JLS, Visser AW, Mari X (1998) Intensive aggregate formation with low vertical flux during an upwelling-induced diatom bloom. Limnol Oceanogr 43:104-116

Kühl M, Glud RN, Ploug H, Ramsing NB (1996) Microenvironmental control of photosynthesis and photosynthesis. coupled respiration in an epilithic cyanobacterial biolfilm. J Phycol 32:799-812

Lassen C, Ploug H, Jørgensen BB (1992) A fibre-optic scalar irradiance microsensor: application for spectral light measurements in sediments. FEMS Microbiol Ecol 86:247-254

Li YH, Gregory S (1974) Diffusion of ions in sea water and in deep-sea sediments. Geochim Cosmochim Acta 38: $703-714$

Logan BE, Alldredge AL (1989) Potential for increased nutrient uptake by flocculating diatoms. Mar Biol 101:443-450

Logan BE, Hunt JR (1987) Advantage to microbes of growth in permeable aggregates in marine systems. Limnol Oceanogr 32:1034-1048

Lubbers GW, Gieskes WWC, del Castilho P, Salmons W, Bril J (1990) Manganese accumulation in the high $\mathrm{pH}$ microenvironment of Phaeocystis sp. (Haptophycae) colonies from the North Sea. Mar Ecol Prog Ser 59:285-293

Passow U, Alldredge AL, Logan BE (1994) The role of particulate carbohydrate exudates in the flocculation of diatom blooms. Deep-Sea Res 41:335-357

Paerl HW, Bebout BM, Prufert LE (1989) Bacterial associations with marine Oscillatoria $\mathrm{sp}$. (Trichodesmium sp.) populations: ecophysiological implications. J Phycol 25:773-784

Paerl HW, Bebout BM (1988) Direct measurements of $\mathrm{O}_{2}$ depleted microzones in marine Oscillatoria sp. (Trichodesmium sp.). Relation to $\mathrm{N}_{2}$-fixing capabilities. Science 241: $441-445$

Ploug $H$, Kühl M, Buchholz B, Jørgensen BB (1997). Anoxic aggregates - an ephemeral phenomenon in the ocean. Aquat Microb Ecol 13:285-294

Ploug H, Grossart HP, Azam F, Jorgensen BB (1999) Photosynthesis, respiration, and carbon turnover in sinking marine snow from surface waters of Southern California Bight: implications for the carbon cycle in the ocean. Mar Ecol Prog Ser (in press)

Prufert-Bebout L, Paerl HW, Lassen C (1993) Growth, nitrogen fixation, and spectral attenuation in cultivated Trichodesmium species. Appl Environ Microbiol 59:1367-1375

Revsbech NP (1989) An oxygen microelectrode with a guard cathode. Limnol Oceanogr 34:474-478

Revsbech NP, Jørgensen BB, Brix O (1981) Primary produc- 
tion of microalgae in sediments by oxygen microprofile, $\mathrm{H}^{14} \mathrm{CO}_{3}$ fixation, and oxygen exchange methods. Limnol Oceanogr 26(4):717-730

R.ichardson LL, Anguilar C, Nealson K (1988) Manganese oxidation in $\mathrm{pH}$ and $\mathrm{O}_{2}$ microenvironments produced by phytoplankton. Limnol Oceanogr 33:352-363

Schlichting H (1987) Boundary-layer theory. McGraw-Hill, Inc, New York

Shanks AL, del Carmen KA (1997) Larval polychaetes are strongly associated with marine snow. Mar Ecol Prog Ser 154:211.-221

Shanks AL, Edmonson EW (1989) Laboratory-made artificial marine snow: a biological model of the real thing. Mar Biol 101:463-470

Shanks AL, Reeder ML (1993) Reducing microzones and sulfide production in marine snow. Mar Ecol Prog Ser 96: $43-47$

Shanks AL, Trent JD (1980) Marine snow: sinking rates and

Editorial responsibility: Tom Fenchel (Contributing Editor), Helsinger, Denmark potential role in vertical flux. Deep-Sea Res 27:137-144

Shanks AL, Walters K (1997) Holoplankton, meroplankton, and meiofauna associated with marine snow. Mar Ecol Prog Ser 156:75-86

Sherwood TK, Pigford RL, Wilke CR (1975) Mass transfer. McGraw-Hill Book Company, New York

Simon M, Alldredge AL, Azam F (1990) Bacterial dynamics on marine snow. Mar Ecol Prog Ser 65:205-211

Smith DC, Simon M, Alldredge AL, Azam F (1992) Intense hydrolytic activity on marine aggregates and implications for rapid particle dissolution. Nature 359:139-141

Stolzenbach KD (1993) Scavenging of small particles by fast-sinking porous aggregates. Deep-Sea Res 40 : 359-369

Tiselius P, Kiørboe T (1998) Colonization of diatom aggregates by the dinoflagellate Noctiluca scintillians. Limnol Oceanogr 43:154-159

White FM (1974) Viscous fluid flow. McGraw-Hill, New York

Submitted: April 21, 1998; Accepted: August 10, 1998

Proofs received from author(s): January 12, 1999 